Saudi Journal of Oral and Dental Research

Abbreviated Key Title: Saudi J Oral Dent Res

ISSN 2518-1300 (Print) |ISSN 2518-1297 (Online)

Scholars Middle East Publishers, Dubai, United Arab Emirates

Journal homepage: https://saudijournals.com/sjodr

\title{
A Survey of Usage Parameters of Nickel-Titanium Rotary Files Among Dentists Working Within Private Clinics in the City of Khartoum, Sudan
}

Mehad Abdallah Osman Ahmed, Elhadi Mohieldin Awooda

Department of Restorative Dentistry, Faculty of Dentistry, University of Medical Sciences and Technology, Sudan

\begin{tabular}{ll}
\hline DOI: $10.36348 /$ sjodr.2020.v05i09.013 & | Received: 30.08 .2020 | Accepted: 07.09 .2020 | Published: 19.09.2020
\end{tabular}

*Corresponding author: Elhadi Mohieldin Awooda

\section{Abstract}

The introduction and development of nickel-titanium rotary instruments are undoubtedly improving the quality of Endodontics treatment. The study aimed to assess, dentist knowledge and practice of using NiTi Rotary instrumentation for the root canal treatment. Also to assess their level of success and failure when using rotary files according to the year of experience and their ability to manage procedural errors in comparison to hand instrumentations. A descriptive crosssectional study among 167 (Endodontists and general practitioners) working in private clinics within Khartoum City, Sudan. A self-administered questionnaire including questions about the uses of NiTi, failures during treatment, and how they managed to overcome. Comparison between variables by Chi-squire test with the level of significance set at a $\mathrm{P}$ value of $\leq 0.05$. The result showed that NiTi rotary files for root canal preparation were used by $72 \%$, with a failure rate of RCTs among 63\%, and the majority $80 \%$ managed to overcome procedural errors. Crown down as a preparation technique was used by $99.2 \%$. The most commonly used rotary system files were pro taper $(83.3 \%)$. The rate of file breakage is directly related to their repeated use, before discarding them and those who managed to treat failure were those with more years of experience and endodontists rather than the general practitioners. In conclusion, the majority of dentists working within private clinics in Khartoum city, use NiTi rotary system for RCT, and years of experience was the major factor in managing the RCT failures.

Keywords: crown down technique, Hand Endodontic files, fractured file, Ni Ti files, rotary system.

Copyright @ 2020: This is an open-access article distributed under the terms of the Creative Commons Attribution license which permits unrestricted use, distribution, and reproduction in any medium for non-commercial use (NonCommercial, or CC-BY-NC) provided the original author and source are credited.

\section{INTRODUCTION}

The long term successful outcome of root canal treatment (RCT) depends on smoothly achieving the objectives of cleaning, shaping, and obturation. Root canal shaping is a cornerstone of the RCT as it facilitates homogenous and complete obturation of the root canal space [1]. The use of newer technologies for canal preparation will be shortening the treatment duration and end up with better outcomes [2]. Dentists who have gained some experience in the use of nickeltitanium rotary instruments will confirm that each file system has its own special characteristics pertaining to advantages and disadvantages and the particular rules for its usage are to be followed [3].

Rotary Nickel-titanium instruments have the advantage of instrumentation with reduced procedural errors when compared to hand stainless steel [4]. Furthermore, the number of users of a root canal preparation instrument may be an important factor in the defect rate [5]. Since the crown-down technique introduced for manual instrumentation in 1984 [6]. In
1988, root canal instruments manufactured from nickeltitanium (NiTi) alloy were introduced to overcome the rigidity of stainless steel [7]. It has proved invaluable for rotary preparation systems using NiTi instruments and its frequency of uses has been increased [8]. However, every file system has a different shaping performance, and it has been suggested that the hybrid use of two or more systems may achieve better shaping efficacy [9]. For clinicians, it is of most importance to select proper instruments and techniques to obtain high cutting efficiency and predictable control over the entire instrumentation procedure without aberrations [10].

The latest data on the use of NiTi files can be obtained from web-based publications reporting leaders, opinions, and surveys of current trends [11]. There is a general perception that $\mathrm{NiTi}$ rotary files have a considerable risk of fracture during use [12]. It could be postulated that rotary NiTi instruments have a potential for separation inside the canal system, and even a new instrument may unexpectedly break when first used. [11] 
During the past 15 years, Nickle titanium (NiTi) rotary instruments have become a part of the standard armamentarium in endodontics. In Sudan, using rotary instruments gains popularity with speedy growing up of training and their education in the undergraduate and postgraduate period. However, there is a little available information on clinical experience, frequency of use/reuse, and incidence of file separation among the operators. Therefore, the objective of this survey was to investigate the preference and usage technique of the NiTi rotary instrument among dentists on the basis of their clinical experience.

\section{MATERIALS AND METHODS}

A Descriptive cross-sectional study among dentists (general dental practitioners and Endodontists) working in private clinics within Khartoum State, Sudan. The study was conducted during the period from 1st of February 2018 to the 1st of March 2018. Dental students, internships, and dentists occupying administrative jobs were excluded. The total number and the list of dentists working within private clinics were obtained from the Ministry of Health, Khartoum State. They were found to be 296 and the sample size was calculated as 167 . The participants were selected by systematic random sampling technique from their list of registration. A self-administered questionnaire including closed-ended questions regarding demographic data, their preference of endodontic files uses the clinical experience of using NITI files, frequency of use/reuse, and incidence of file separation.

The selected dentists were requested to participate voluntarily; all accepted to participate and they signed informed written consent. The study was approved by the Ethical Committee of the University of Medical Sciences and Technology and permission was taken from the authorities in the Ministry of Health (Khartoum State).

Data were analyzed by SPSS (statistical package for social science) using version 21. SPSS Inc., Chicago Ill., USA. A comparison between different non-parametric data was done by the Chi-square test with the level of significance set at $\mathrm{P}$-value $<0.05$.

\section{RESULTS}

The descriptive statistics of the results as displayed in Tables (1-3). The total number of participants was 167 Dentists (Endodontists 46 (27.5\%) and General dental practitioners were 121 (72.5\%).) age group ranged from 24 years old to 55 years.

Majority $120(72.7 \%)$ of participants with year of experience of 5-10 years. Also the usage of NiTi Rotary system with the group of current users being the highest $120(71.9 \%)$, followed by former users 26 $(15.6 \%)$ and the lowest being dentists who never used rotary before $21(12.6 \%)$. The Protaper Rotary system is the most used system among other Endodontic rotary systems $100(83.3 \%)$ and the least system used is the pro taper gold at $1(0.8 \%)$. The most common cause of failure among dentists in private clinics turned to be a broken instrument $105(52.2 \%)$ followed by Perforation by $81(40.3 \%)$ with the least cause being fractured tooth among $15(7.5 \%)$. Table-1 showed the comparison between general practitioners and endodontists regarding the number of using rotary files before discharging was higher among Endodontists with the Pvalue of 0.001 .

Table-1: Shows the number of times endodontists or a general practitioner uses rotary endodontics files before discarding them

\begin{tabular}{|l|l|l|l|l|}
\hline & $(\mathbf{1}$ tooth) & $\mathbf{( 2}$ teeth $)$ & $\mathbf{( 3 - 4}$ teeth $)$ & (5 or more teeth) \\
\hline Endodontists & $2(24.3 \%)$ & $12(26.1 \%)$ & $30(65.2 \%)$ & $2(4.3 \%)$ \\
\hline General practitioner & $3(3.9 \%)$ & $40(52.6 \%)$ & $22(28.9 \%)$ & $11(14.5 \%)$ \\
\hline
\end{tabular}

Table-2 showed the failed cases encountered by Endodontists and General practitioners where Endodontists have a higher level of failure, but it was not statistically significant, with a P-Value of 0.643 .
Years of experience in performing root canal treatments and the ability to manage their failure was displayed in Table-3.

Table-2: Comparison between Endodontists and general practitioners regarding failed cases they encountered

\begin{tabular}{|l|c|c|c|c|c|}
\hline \multicolumn{7}{|c|}{ failed cases where canals prepared by rotary files } \\
\hline & (None) & $(2-5$ cases ) & (More than 5 cases ) & $\begin{array}{l}\text { don't } \\
\text { remember }\end{array}$ & $\begin{array}{l}\text { P- } \\
\text { Value }\end{array}$ \\
\hline Endodontists & $2(4.3 \%)$ & $29(63.0 \%)$ & $3(6.5 \%)$ & $12(26.1 \%)$ & 0.643 \\
\hline General practitioner & $6(8.1 \%)$ & $45(60.8 \%)$ & $2(2.7 \%)$ & $21(28.4 \%)$ & \\
\hline
\end{tabular}

Table-3: Association between the years of experience of a dentist and their ability to manage failures

\begin{tabular}{|l|l|l|l|}
\hline \multicolumn{2}{|c|}{} & \multicolumn{2}{|c|}{ Manage to correct } \\
\cline { 3 - 4 } \multicolumn{2}{|c|}{} & Yes & No \\
\hline \multirow{3}{*}{ years of experience } & Less than two years & $(5) 35.7 \%$ & $(9) 64.3 \%$ \\
\cline { 2 - 4 } & Less than 5 years & $(22) 78.6 \%$ & $(6) 21.4 \%$ \\
\cline { 2 - 4 } & (5-10years) & $(75) 96.2 \%$ & $(3) 3.8 \%$ \\
\hline
\end{tabular}




\section{DISCUSSION}

In the endodontics, techniques for cleaning and shaping of root canals differ; and the best procedure for all conditions has not been established. On the other hand, the introduction of new file designs and materials has increased dramatically during the past few years. At its best, recent NiTi rotary systems solve most of the deficiencies of traditional stainless steel instruments. This study aims to assess the dental practice when using NiTi Rotary system during RCT in regards to dentists (General practitioners and endodontists) knowledge, levels of success and failures, and the ability to managing failures all according to their year of experience.

Practicing dentistry in private clinics in Khartoum represents the core of advanced treatment modalities and especially when performing root canal treatment, it necessitates the utilization of the available new technology that shortening treatment duration and saving time for both patients and the clinicians. Rotary files can achieve this goal as similar to the result of the study by Hülsmann et al., [13] our results reveal that the NiTi rotary system is very high among endodontists and general practitioners. This is probably due to the high efficacy and accuracy of the machine preparation and saving much time allocated for the treatment. The study also shows that Pro Taper system is the most used when compared to other systems, this may be, because of its availability in the market, cheap and reasonable price, and easiness of its uses that resulted in a better adaptation to the canal geometry. This result is consistent with the results obtained by Guobin Yang et al., [14] but contradict the study conducted by the American Board of Endodontists that concluded frequently used rotary files were ProFile or ProTaper $[10,12]$.

The most common cause of RCT failure when using $\mathrm{Ni} \mathrm{Ti}$ instrument, is its breakage. Fracture of rotary NiTi instruments is approximately $1.0 \%$ with a range of $0.4 \%-3.7 \%[15,16]$. The reason behind fracture instrument may be probably due to fatigue and forceful instrumentation among other reasons supported by other studies $[5,17]$. Our study also revealed that overuse of the same file doesn't cause failure and the failed cases among endodontists and general practitioner in regards to their repeated use of the file has no significant influence on the failure, this result is similar to Seago et al., study who reported that the repeated simulated clinical use has no effect on the cutting efficiency [18]. It is proven by this study that the years of experience of a dentist have a direct effect on the dentist's ability to manage the failures and hardships encountered during treatment probably due to the increased knowledge through the years and continues the clinical practice.
The limitations of this study are that it is a descriptive cross-sectional study that is based on a questionnaire and in this case, there is no telling of the participant's honesty also the study is limited to certain private clinics within Khartoum city and not included the whole country. So the results don't cover all opinions and facts of other endodontists and general practitioners.

While the strength of this study could be the use of a survey questionnaire that allowed us to gather a significant amount of data at a relatively short time and little cost. Also, the study populations were gathered from one area, which made the process of Data collection easier. The study also could stimulate scholars to assess the quality of rotary instruments manufacture by fake companies and usually purchased in poor countries like Sudan, which may result in a high frequency of endodontic failure.

\section{CONCLUSION}

This study concluded that dentists in private clinics in Khartoum state have a high usage of NiTi Rotary system in Root canal treatment, with the most common type used is a pro taper file system. The failed cases among endodontists and general practitioners with regards to their repeated use of the Pro taper files have no significant influence on the failure of root canal treatments in general.

Conflict of interest: Both authors declare that they have no conflict of interest.

\section{REFERENCES}

1. Silvani, M., Brambilla, E., Cerutti, A., Amato, M., \& Gagliani, M. (2013). Root canal treatment quality in undergraduate program: a preliminar report on $\mathrm{NiTi}$ reciprocating files. Giornale Italiano di Endodonzia, 27(1), 33-37.

2. Elham, F. G., \& Sedigheh, Z. (2012). The use of instruments by Iranian endodontics and general practioners. The open dentistry journal, 6, 105110.

3. Walsch, H. (2004). The hybrid concept of nickeltitanium rotary instrumentation. Dental Clinics, 48(1), 183-202.

4. Gavini, G., Santos, M. D., Caldeira, C. L., Machado, M. E. D. L., Freire, L. G., Iglecias, E. F., ... \& Candeiro, G. T. D. M. (2018). Nickeltitanium instruments in endodontics: a concise review of the state of the art. Brazilian oral research, 32 .

5. García-Font, M., Duran-Sindreu, F., MorelloCastro, S., Mercade-Bellido, M., Bueno-Martínez, R., \& Roig-Cayón, M. (2012). Failure of ProTaper rotary Ni-Ti instruments used by undergraduate students. Journal of clinical and experimental dentistry, 4(4), e199-203. 
6. Morgan, L. F., \& Montgomery, S. (1984). An evaluation of the crown-down pressureless technique. Journal of Endodontics, 10(10), 491498.

7. Walia, H., Brantley, W. A., \& Gerstein, H. (1988). An initial investigation of the bending and torsional properties of Nitinol root canal files. Journal of endodontics, 14(7), 346-351.

8. Azar, M. R., \& Mokhtare, M. (2011). Rotary Mtwo system versus manual K-file instruments: efficacy in preparing primary and permanent molar root canals. Indian Journal of Dental Research, 22(2), 363.

9. Bürklein, S., Hinschitza, K., Dammaschke, T., \& Schäfer, E. (2012). Shaping ability and cleaning effectiveness of two single- file systems in severely curved root canals of extracted teeth: Reciproc and WaveOne versus Mtwo and ProTaper. International endodontic journal, 45(5), 449-461.

10. Bird, D. C., Chambers, D., \& Peters, O. A. (2009). Usage parameters of nickel-titanium rotary instruments: a survey of endodontists in the United States. Journal of endodontics, 35(9), 1193-1197.

11. Madarati, A. A., Watts, D. C., \& Qualtrough, A. J. E. (2008). Opinions and attitudes of endodontists and general dental practitioners in the UK towards the intracanal fracture of endodontic instruments: part 1. International endodontic journal,41(8), 693-701.

12. Lee, W., Song, M., Kim, E., Lee, H., \& Kim, H. C. (2012). A survey of experience-based preference of Nickel-Titanium rotary files and incidence of fracture among general dentists. Restorative dentistry \& endodontics, 37(4), 201-206.

13. Hülsmann, M., \& Bluhm, V. (2004). Efficacy, cleaning ability and safety of different rotary NiTi instruments in root canal retreatment. International Endodontic Journal, 37(7), 468-476.

14. Yang, G., Yuan, G., Yun, X., Zhou, X., Liu, B., \& $\mathrm{Wu}$, H. (2011). Effects of Two nickel-titanium instrument systems, Mtwo versus ProTaper universal, on root canal geometry assessed by micro-computed tomography. Journal of Endodontics, 37(10), 1412-1416.

15. Al- Fouzan, K. S. (2003). Incidence of rotary ProFile instrument fracture and the potential for bypassing in vivo. International endodontic journal, 36(12), 864-867.

16. Pettiette, M. T., Conner, D., \& Trope, M. (2002). Procedural errors with the use of nickel-titanium rotary instruments in undergraduate endodontics. $J$ Endod, 28(3), 259.

17. Tewari, R. K., Kapoor, B., Kumar, A., Mishra, S. K., \& Mukhtar-Un-Nisar-Andrabi, S. (2017). Fracture of rotary nickel titanium instruments. Journal of Oral Research and Review, 9(1), 37-44.

18. Seago, S. T., Bergeron, B. E., Kirkpatrick, T. C., Roberts, M. D., Roberts, H. W., Himel, V. T., \& Sabey, K. A. (2015). Effect of repeated simulated clinical use and sterilization on the cutting efficiency and flexibility of Hyflex CM nickeltitanium rotary files. Journal of endodontics, 41(5), 725-728. 